\title{
Urgent improvements needed to diagnose and manage Lynch syndrome
}

Kevin J Monahan consultant gastroenterologist and honorary senior clinical lecturer ${ }^{1}$, Deborah Alsina chief executive ${ }^{2}$, Simon Bach consultant colorectal surgeon ${ }^{3}$, James Buchanan health economist ${ }^{4}$, John Burn professor of clinical genetics ${ }^{5}$, Sue Clark professor and consultant colorectal surgeon $^{6}$, Peter Dawson president ${ }^{7}$, Bianca De Souza clinical genetics registrar ${ }^{8}$, Farhat V N Din senior lecturer and colorectal surgeon ${ }^{9}$, Sunil Dolwani clinical senior lecturer and vice president ${ }^{10}$, Malcolm G Dunlop head of colon cancer genetics ${ }^{11}$, James East consultant gastroenterologist and honorary senior clinical lecturer ${ }^{12}$, D Gareth Evans professor of medical genetics and cancer epidemiology ${ }^{13}$, Nicola Fearnhead consultant colorectal surgeon and chair of research and committee $^{14}$, lan M Frayling consultant in genetic pathology ${ }^{15}$, Rob Glynne-Jones consultant clinical oncologist $^{16}$, James Hill professor of colorectal surgery ${ }^{17}$, Richard Houlston professor ${ }^{18}$, Mark Hull professor and consultant gastroenterologist ${ }^{19}$, Fiona Lalloo consultant clinical geneticist ${ }^{20}$, Andrew Latchford consultant gastroenterologist and honorary senior clinical lecturer ${ }^{21}$, Suzy Lishman president $^{22}$, Phil Quirke professor and head of pathology and tumour biology ${ }^{23}$, Colin Rees professor and vice president (chair of endoscopy) ${ }^{24}$, Matt Rutter professor and consultant gastroenterologist ${ }^{25}$, Peter Sasieni professor of biostatistics and cancer epidemiology ${ }^{26}$, Asha Senapati consultant colorectal surgeon and chairman ${ }^{27}$, Doug Speake colorectal surgeon ${ }^{28}$, Huw Thomas professor of gastrointestinal genetics ${ }^{29}$, lan Tomlinson professor of genetics ${ }^{30}$

${ }^{1}$ Family History of Bowel Cancer Clinic, West Middlesex University Hospital, Chelsea and Westminster Hospitals NHS Trust; Imperial College London, London, UK; ${ }^{2}$ Bowel Cancer UK; ${ }^{3}$ Queen Elizabeth Hospital, Birmingham; ${ }^{4}$ University of Oxford; ${ }^{5}$ Newcastle University; ${ }^{6}$ St Mark's Hospital; ${ }^{7}$ Association of Coloproctology for Great Britain and Ireland; ${ }^{8}$ North West Thames Regional Genetics Service; ${ }^{9}$ Western General Hospital, Edinburgh; ${ }^{10} \mathrm{C}$ ardiff University and Welsh Association of Gastroenterology and Endoscopy; ${ }^{11}$ Colon Cancer Genetics Group and Academic Coloproctology, Institute of Genetics and Molecular Medicine; ${ }^{12}$ Oxford University Hospitals; ${ }^{13}$ University of Manchester; ${ }^{14}$ Cambridge University Hospitals NHS Foundation Trust and Association of Coloproctology of Great Britain and Ireland; ${ }^{15}$ University Hospital of Wales; ${ }^{16}$ Mount Vernon Cancer Centre; ${ }^{17}$ Central Manchester University Hospitals; ${ }^{18}$ Institute of Cancer Research, London; ${ }^{19}$ University of Leeds and Leeds Teaching Hospitals NHS Trust; ${ }^{20}$ Manchester Centre for Genomic Medicine, Central Manchester University Hospitals NHS Foundation Trust; ${ }^{21}$ St Mark's Hospital and Imperial College London; ${ }^{22}$ Royal College of Pathologists; ${ }^{23}$ University of Leeds; ${ }^{24}$ British Society of Gastroenterology; ${ }^{25}$ University Hospital of North Tees; ${ }^{26}$ Queen Mary University of London; ${ }^{27}$ Bowel Disease Research Foundation; ${ }^{28}$ Western General Hospital, Edinburgh; ${ }^{29}$ St Mark's Hospital, Imperial College London; ${ }^{30}$ University of Oxford

Lynch syndrome is currently under-recognised, underdiagnosed, and undermanaged, so opportunities to reduce cancer mortality are often missed. The new guideline from the National Institute for Health and Care Excellence recommends universal testing for Lynch syndrome in all people newly diagnosed as having colorectal cancer. ${ }^{1}$ This should prevent several hundred colorectal cancers annually, but several issues hinder good care of patients with Lynch syndrome in the UK.

Current practice in diagnostic testing for Lynch syndrome is variable. Many hospitals do not adhere to the current Royal College of Pathologists' colorectal cancer dataset, which recommends reflex tumour testing for Lynch syndrome in 
patients diagnosed under $50 .^{2}$ All hospitals should ensure that multidisciplinary teams for colorectal cancer are fully engaged in delivering this integrated service.

Known carriers of the gene mutation for the syndrome are inadequately managed, with poor awareness of this condition in the NHS. ${ }^{3}$ Patients are not being seen quickly enough. Many do not have personalised care strategies, and follow-up is inadequate.

Patients with Lynch syndrome often fail to receive consistent management. ${ }^{4}$ Carriers require coordinated, timely, and high quality care to reduce their cancer risk.

In March 2016 Bowel Cancer UK organised a clinical consensus meeting to tackle these issues. We call for a national registry of people with Lynch syndrome; a quality assured colonoscopic surveillance programme for people with Lynch syndrome; and a dedicated clinical champion for hereditary colorectal cancer in each multidisciplinary team to oversee local service delivery.
In short, a multifaceted and multimodel strategy is required to improve outcomes for people at high risk of colorectal cancer.

Competing interests: SB is a consultant for Ethicon, Cincinatti. John Burn and his team have a patent pending on a new high throughput MSI assay.

Full response at: http://www.bmj.com/content/356/bmj.j998/rr.

1 Gulland A. All patients with colorectal cancer should be tested for genetic condition, NICE advises. BMJ 2017;356:j998. doi:10.1136/bmj.j998 pmid:28235818.

2 Royal College of Pathologists. Dataset for colorectal cancer histopathology reports (3rd edition). https://www.rcpath.org/resourceLibrary/dataset-for-colorectal-cancerhistopathology-reports--3rd-edition-html

3 Monahan KJ, Clark SK. British Society of Gastroenterology (BSG) Cancer Group. A national survey of hereditary colorectal cancer services in the UK. Frontline Gastroenterol 2014;356:130-4. doi:10.1136/flgastro-2013-100362.

4 Bowel Cancer UK. Improving services for Lynch syndrome: who's responsible? 2016. www.bowelcanceruk.org.uk/campaigning/never-too-young/lynch-syndrome/

Published by the BMJ Publishing Group Limited. For permission to use (where not already granted under a licence) please go to http://group.bmj.com/group/rights-licensing/ permissions 